\title{
Video instructions improve accuracy of self-measures of waist circumference compared with written instructions
}

\author{
Dara F McEneaney ${ }^{1}$ and Susan C Lennie ${ }^{2, *}$ \\ ${ }^{1}$ Community Dietetic Department, NHS Grampian, Westholme, Woodend Hospital Site, Queens Road, \\ Aberdeen AB15 6LS, UK: ${ }^{2}$ School of Pharmacy and Life Sciences, Robert Gordon University, St Andrew Street, \\ Aberdeen AB25 1HG, UK
}

Submitted 24 August 2010: Accepted 14 February 2011: First published online 31 March 2011

\begin{abstract}
Objective: To determine whether video-based instructions improve the accuracy of self-measures of waist and hip circumference compared with written instructions. Design: Population-based, cross-sectional study. Self-measurements of waist circumference (WC) and hip circumference (HC) of fifty-seven participants randomly allocated to receive either written instruction or video instruction were compared with those of a trained technician.

Setting: Aberdeen, Scotland, and Brussels, Belgium, between February and April 2010.

Subjects: Adults aged 18-62 years with a high level of English language and no prior training in anthropometry.

Results: WC was significantly overestimated by the written method $(1.75 \mathrm{~cm}$ bias; $P=0 \cdot 007)$ but not the video method $(0.95 \mathrm{~cm}$ bias; $P=0 \cdot 239)$. HC was significantly underestimated in both written $(-0.35 \mathrm{~cm}$ bias; $P=0.009)$ and video methods $(-0.75 \mathrm{~cm}$ bias; $P=0.046)$. Reliability was not significantly affected by age, sex, BMI or WC. Bland-Altman plots demonstrated wide limits of agreement for WC $(-6 \cdot 83,6 \cdot 08 \mathrm{~cm}$ for written method; $-10 \cdot 14,6 \cdot 72 \mathrm{~cm}$ for video method) and HC $(-12 \cdot 85,1 \cdot 60 \mathrm{~cm}$ for written method; $-10 \cdot 82,2 \cdot 50 \mathrm{~cm}$ for video method).

Conclusions: Video technology can support more accurate self-measurements of anthropometric data in epidemiological studies. Further research is warranted using larger and more heterogeneous samples in order that results can be generalised.
\end{abstract}

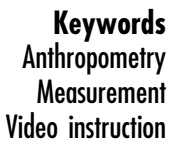

Keywords

Measurement

Video instruction
Obesity is becoming increasingly prevalent worldwide. Historically, BMI and waist:hip ratio (WHR) have been used as indices of obesity and related disease risk in epidemiological studies ${ }^{(1)}$. However, waist circumference (WC) is a better indicator of body fat distribution than $\mathrm{BMI}^{(2)}$ and it has been demonstrated that central deposition of adipose tissue can better predict risk of disease $^{(3)}$. Additionally, WC is a more precise marker of central adiposity than WHR as WHR will remain constant if WC and hip circumference (HC) increase proportionally. Furthermore, HC has been found to be independently associated with disease, with larger HC providing a protective effect for a given $\mathrm{WC}^{(1,4)}$. Therefore measurement of both WC and HC can act as simple indicators for disease risk.

Anthropometric measurements such as WC and HC are traditionally collected by a trained technician; however, this method can be time-consuming and costly to conduct. For this reason epidemiological studies often rely on self-administered questionnaires to obtain data. Previous studies have demonstrated reliability of self-measures of anthropometry ${ }^{(5-8)}$ but vary in terms of over- and underestimation of body girths. Correlations between self- and technician measurements have ranged from 0.79 to $0.98^{(7,8)}$ for WC and from 0.74 to $0.96^{(9,10)}$ for $\mathrm{HC}$; mean errors have ranged from $0 \cdot 14 \mathrm{~cm}$ to $5 \cdot 2 \mathrm{~cm}^{(11,12)}$ for WC and from $0.56 \mathrm{~cm}$ to $1.8 \mathrm{~cm}^{(9,10)}$ for $\mathrm{HC}$; and limits of agreement have ranged from $-5 \cdot 0,4 \cdot 2 \mathrm{~cm}$ to $-14 \cdot 9$, $8 \cdot 9 \mathrm{~cm}^{(6,13)}$. These studies therefore support the utilisation of self-measurements in providing a simple and inexpensive method to enable reliable data collection in epidemiological studies.

Previous studies examining the accuracy of selfmeasured body circumferences compared with technician measurements have predominantly provided written instructions to participants. However, instruction provided via video technology, with directive voice-over, may improve accuracy. Providing instruction in a dual format, i.e. audio and visual, can improve the effectiveness of working memory ${ }^{(14)}$. A recent study ${ }^{(15)}$ described a computer-based video tutorial for teaching self-measurement of WC, compared with technician measurement, and found this method to be reliable and effective for teaching WC to untrained individuals. Compared with written 
instruction, video instruction has been shown to improve skill, performance and understanding in a range of applications including electric toothbrush usage ${ }^{(16)}$, laboratory experiments $^{(17)}$ and patient education ${ }^{(18)}$

Within developed countries computer ownership and Internet access is rising annually. Of UK households, $72 \%$ owned a home computer in 2008 and $70 \%$ had Internet access in $2009^{(19,20)}$. Computers can therefore provide the majority of the population with low-cost and easy access to a range of educational materials ${ }^{(21)}$, providing a simple means with which to follow video instruction provided as part of epidemiological studies.

To date, only one published study has examined the accuracy of self-measurements of body circumferences using video instruction ${ }^{(15)}$. No previous studies have compared instruction formats. The aim of the present study therefore was to investigate if video instruction can improve the accuracy of self-measurement of WC and HC compared with written instruction. It was hypothesised that using computerbased video technology instructions for self-measures of anthropometry would improve accuracy compared with written instruction. Secondary objectives were to assess whether reliability was affected by sex, age, BMI and WC. The present study is the first one known to compare different methods of teaching girth measurement technique to assess whether instruction methods differ in their ability to enable accurate and reliable measurements by participants.

\section{Method}

\section{Participants}

Participants were recruited via posters, an email bulletin distributed in a large educational establishment and word of mouth. Inclusion criteria were: (i) a high level of English language, i.e. native English speaker or minimum IELTS (International English Language Testing System) or TOEFL $^{\circledR}$ (Test of English as a Foreign Language ${ }^{\mathrm{TM}}$ ) score of 6.0 or 550 , respectively; and (ii) no prior training in anthropometry. All volunteers received an information sheet detailing the study background, process, and clothing requirements (loose, light clothing) prior to providing written consent to participate. The participants were randomised to receive either written instructions ('written method') or video instructions ('video method').

\section{Antbropometry}

Participants were advised to follow instructions carefully; to read/watch them as many times as required until sufficiently confident to take measurements; to measure each parameter in duplicate to the nearest $0.1 \mathrm{~cm}$; and to document measurements on the questionnaire provided, including how many times they read/watched each set of instructions. In addition, participants also completed a questionnaire detailing age, sex and education level.

A flexible steel tape measure (Lufkin W606PM; Cooper Industries, Lexington, SC, USA) and a mirror were provided to participants; the technician ensured participants could clearly see their reflection in the mirror. Written or video instructions, based on an established protocol $^{(22)}$, were provided.

Written instructions were adapted from a previous study $^{(23)}$ and were drafted to a Flesch-Kincaid Grade Level of $7 \cdot 4$. A diagram was included with the written instructions highlighting the approximate location of measurements. Professional video instructions were developed and incorporated into a PowerPoint ${ }^{\circledR} 2007$ (Microsoft Corporation, Redmond, WA, USA) presentation. Two separate videos were included, WC (32 s duration; Fig. 1) and HC (35 s duration; Fig. 2), and included audio and visual instructions of measurement technique. Participants in the video method were verbally instructed to click on the computer screen to start each video but were left alone to complete their measurements; the technician was available should the participants encounter any problems. Once complete, the technician returned to the room and measured participants' WC and HC in duplicate according to the same protocol. The technician was blinded to participants' selfmeasurements during the experimental process. WC was measured at the narrowest point of the abdomen and $\mathrm{HC}$ measured at the level of the greatest posterior protuberance of the buttocks ${ }^{(22)}$. Body weight was measured with shoes
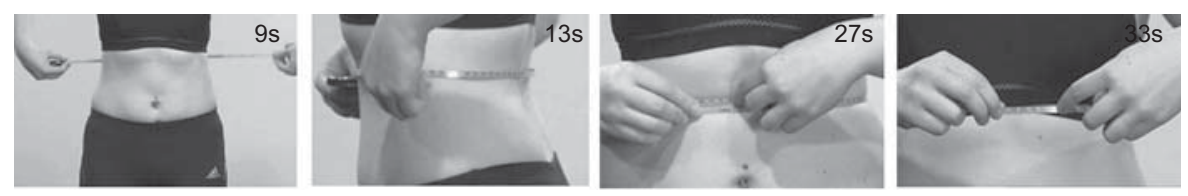

Fig. 1 Video captures of waist circumference measurement
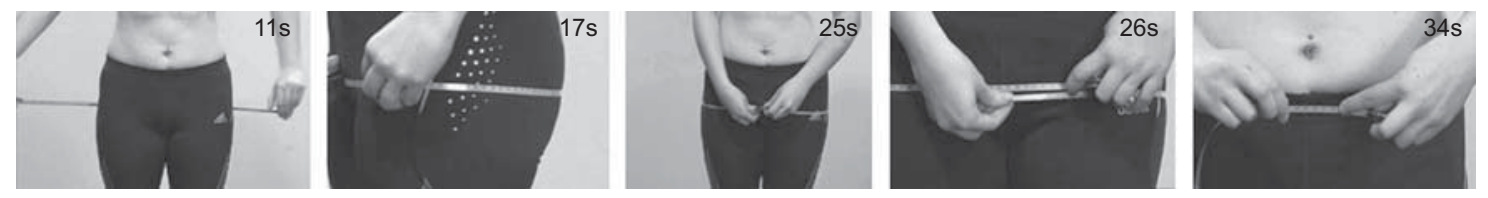

Fig. 2 Video captures of hip circumference measurement 
removed, to the nearest $0.5 \mathrm{~kg}$, using reliable weighing scales (Seca Mechanical Scales; Seca, Hamburg, Germany or Soehnle Mechanical Scales, Soehnle, Backnang, Germany). Height was measured with shoes removed, to the nearest $0 \cdot 1 \mathrm{~cm}$, using a portable stadiometer (Leicester Height Measure; Seca Ltd, Birmingham, UK). BMI was subsequently calculated. All measurements were taken by a single, trained researcher (technician) with experience of undertaking anthropometric measurements in both clinical and academic settings prior to the study. In addition, the technician received additional training and assessment by a Level 4 Criterion Anthropometrist, accredited by the International Society for the Advancement of Kinanthropometry (ISAK), to determine interand intra-tester accuracy and reliability.

\section{Data analysis}

The mean of duplicate measurements for both self- and technician measurements were used in the analysis. Participants failing to complete the measurement procedure were excluded from analysis. Where only single measurements were provided for both WC and HC these measurements were used for analysis. Where participants used the wrong side of the tape measure to record their measurements (imperial rather than metric), this was converted to metric units for inclusion in the analysis.

Participants were stratified into sub-categories relating to sex, age, BMI and WC in order to identify potential differences in accuracy which may exist according to these characteristics. For the purpose of analysis participants were split into two groups for age ( $\leq 26$ years, $>26$ years), BMI $\left(<25 \mathrm{~kg} / \mathrm{m}^{2}, \geq 25 \mathrm{~kg} / \mathrm{m}^{2}\right)$ and WC $(<80 \mathrm{~cm}, \geq 80 \mathrm{~cm}$ for women and $<94 \mathrm{~cm}, \geq 94 \mathrm{~cm}$ for men). Cut-off points for BMI and WC were those specified in current guidelines ${ }^{(24)}$.

Data were screened for normality and Mann-Whitney $U$ tests and $\chi^{2}$ analysis used to assess distribution of the data across instruction methods. The Mann-Whitney $U$ test was used to assess whether self- and technician-measured circumferences differed within sex, age, BMI and WC sub-categories within each instruction method. Spearman's rank correlation coefficients examined the relationship between accuracy of measurement and number of times instructions were reviewed. The Wilcoxon signed-rank test was used to assess differences between self- and technician-measured circumferences. Due to the skewed nature of the data, the average differences between selfand technician measurements (biases) are reported in terms of median error. Agreement between measurements was examined in relation to instruction method, sex, age, BMI and WC using Bland and Altman's ${ }^{(25,26)}$ non-parametric approach to the limits of agreement method. Statistical significance was accepted at $P<0 \cdot 05$. All analyses were performed using the SPSS for Windows statistical software package version $15 \cdot 0$ (SPSS Inc., Chicago, IL, USA).

The study was approved by the Institutional Ethical Review Panel in February 2010. All information obtained was confidential and participants were free to withdraw from the study at any time.

\section{Results}

Intra-tester precision of the trained researcher was assessed using the technical error of measurement, which was $0 \cdot 2 \%$ for $\mathrm{WC}$ and $0 \cdot 14 \%$ for $\mathrm{HC}$.

\section{Participant characteristics}

Table 1 shows both the mean and median values for participant characteristics. Following stratification of participants based on instruction method, $\chi^{2}$ analysis confirmed that the two groups did not differ significantly in terms of sex, age group, BMI group and WC group. Owing to the homogeneity of the sample in terms of educational status, this variable was not considered in subsequent analysis. Only one participant failed to complete the measurements and was therefore excluded from subsequent analysis.

Table 1 Characteristics of the participants by instruction method: adults aged 18-62 years in Aberdeen (Scotland) and Brussels (Belgium), with a high level of English language and no prior training in anthropometry, February-April 2010

\begin{tabular}{|c|c|c|c|c|c|c|c|c|c|c|c|}
\hline \multirow[b]{2}{*}{ Characteristic } & \multirow[b]{2}{*}{ Range } & \multicolumn{3}{|c|}{ All participants ( $n 57)$} & \multicolumn{3}{|c|}{ Written method ( $n$ 29) } & \multicolumn{3}{|c|}{ Video method $(n 28)$} & \multirow[b]{2}{*}{$P$ value } \\
\hline & & Mean & SD & Median & Mean & SD & Median & Mean & SD & Median & \\
\hline Age (years) & 18-62 & $33 \cdot 3$ & $14 \cdot 6$ & $26 \cdot 0$ & $33 \cdot 3$ & $15 \cdot 2$ & $26 \cdot 0$ & $33 \cdot 2$ & $14 \cdot 3$ & $26 \cdot 0$ & 0.930 \\
\hline WC $(\mathrm{cm})$ & $61 \cdot 0-125 \cdot 7$ & $78 \cdot 5$ & $10 \cdot 8$ & $78 \cdot 6$ & $78 \cdot 0$ & $13 \cdot 6$ & $77 \cdot 6$ & $78 \cdot 9$ & $6 \cdot 9$ & $80 \cdot 0$ & $0 \cdot 247$ \\
\hline $\mathrm{HC}(\mathrm{cm})$ & $84 \cdot 0-119 \cdot 5$ & $98 \cdot 4$ & $6 \cdot 4$ & $98 \cdot 5$ & $98 \cdot 5$ & $7 \cdot 8$ & $98 \cdot 0$ & $98 \cdot 4$ & $4 \cdot 7$ & $98 \cdot 5$ & 1.000 \\
\hline $\begin{array}{l}\text { No. times instructions } \\
\text { read/watched (WC) }\end{array}$ & $1-3$ & $1 \cdot 7$ & 0.7 & $2 \cdot 0$ & $1 \cdot 8$ & 0.6 & $2 \cdot 0$ & $1 \cdot 5$ & $0 \cdot 7$ & $1 \cdot 0$ & 0.133 \\
\hline $\begin{array}{l}\text { No. times instructions } \\
\text { read/watched }(\mathrm{HC})\end{array}$ & $1-4$ & $1 \cdot 6$ & 0.7 & $1 \cdot 0$ & $1 \cdot 7$ & $0 \cdot 7$ & $2 \cdot 0$ & $1 \cdot 4$ & $0 \cdot 7$ & $2 \cdot 0$ & 0.009 \\
\hline Height $(\mathrm{cm})$ & $148 \cdot 8-199 \cdot 9$ & $169 \cdot 8$ & $10 \cdot 2$ & $168 \cdot 0$ & $169 \cdot 9$ & $10 \cdot 4$ & $168 \cdot 0$ & $169 \cdot 6$ & $10 \cdot 2$ & $169 \cdot 1$ & 0.805 \\
\hline Weight (kg) & $43 \cdot 5-119 \cdot 0$ & $68 \cdot 1$ & $13 \cdot 3$ & $67 \cdot 0$ & $67 \cdot 9$ & $16 \cdot 3$ & $66 \cdot 0$ & $68 \cdot 4$ & $9 \cdot 6$ & $68 \cdot 8$ & $0 \cdot 380$ \\
\hline BMI $\left(\mathrm{kg} / \mathrm{m}^{2}\right)$ & $16 \cdot 4-39 \cdot 5$ & $23 \cdot 6$ & $3 \cdot 6$ & $23 \cdot 6$ & $23 \cdot 4$ & $4 \cdot 6$ & $21 \cdot 5$ & $23 \cdot 7$ & $2 \cdot 2$ & $24 \cdot 5$ & 0.371 \\
\hline
\end{tabular}

WC, waist circumference; HC, hip circumference.

tMann-Whitney $U$ test for the difference between written and video methods. 

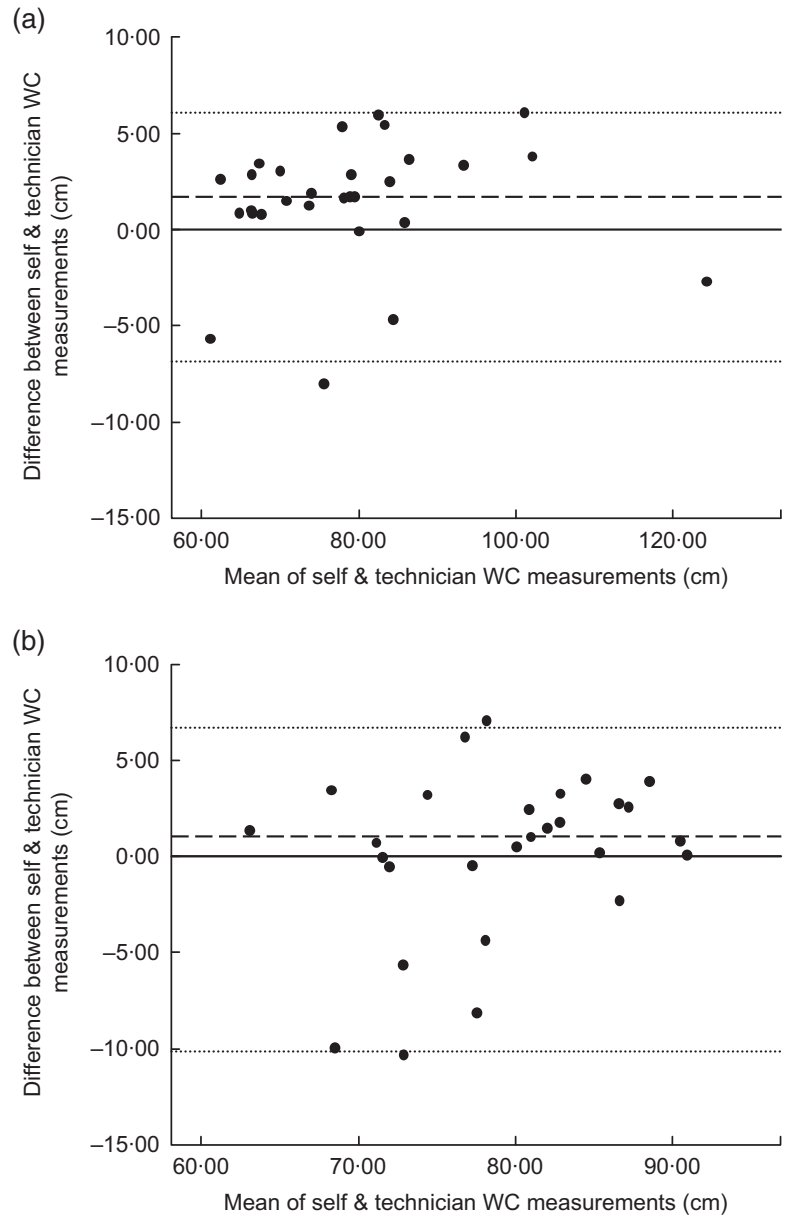

Fig. 3 Bland-Altman plot of biases of waist circumference (WC) measurement with limits of agreement, comparing selfmeasurements with technician measurements for the written method (a) and the video method (b). Negative differences indicate underestimation; positive differences indicate overestimation; — indicates zero bias; - - - indicates median error; $\cdots$ indicates the 5 th and 95 th percentile limits of agreement

\section{Waist circumference}

Figure 3 illustrates the biases and limits of agreement for all participants within the written and video methods. Table 2 shows the biases and limits of agreement between self- and technician measurements for different participant characteristics within each instruction method. The mean WC was overestimated in all sub-categories regardless of instruction method. There were no significant differences between the biases within the subcategories for sex, age, BMI or WC for either instruction method. Accuracy was greater for WC in the video method and no significant differences were observed between self- and technician measurements for participants within any sub-category in the video method only.

The number of times instructions were read/watched for WC correlated significantly with WC bias in the video method $\left(r_{\mathrm{S}}=0.387 ; P=0.042\right)$ and with the number of times instructions were read/watched for $\mathrm{HC}$ in the
Table 2 Biases and limits of agreement of waist circumference measurements in video and written instruction methods

\begin{tabular}{|c|c|c|c|c|}
\hline & $n$ & Bias $(\mathrm{cm}) \dagger$ & $P$ value $\ddagger$ & LOA $(\mathrm{cm}) \S$ \\
\hline \multicolumn{5}{|l|}{ Written method } \\
\hline All participants & 29 & $1 \cdot 75$ & $0 \cdot 007^{\star \star}$ & $-6 \cdot 83,6 \cdot 08$ \\
\hline \multicolumn{5}{|l|}{ Sex } \\
\hline Male & 10 & $1 \cdot 75$ & $0 \cdot 007^{\star \star}$ & $-0.05,6 \cdot 15$ \\
\hline Female & 19 & $2 \cdot 55$ & $0 \cdot 131$ & $-8 \cdot 00,6 \cdot 00$ \\
\hline \multicolumn{5}{|l|}{ Age } \\
\hline$\leq 26$ years & 16 & $1 \cdot 73$ & $0 \cdot 008^{\star *}$ & $-5 \cdot 65,5 \cdot 50$ \\
\hline$>26$ years & 13 & $2 \cdot 55$ & $0 \cdot 196$ & $-8 \cdot 00,6 \cdot 15$ \\
\hline \multicolumn{5}{|l|}{ BMI } \\
\hline$<25 \mathrm{~kg} / \mathrm{m}^{2}$ & 19 & $1 \cdot 70$ & $0.003^{\star \star \star}$ & $-5 \cdot 65,5 \cdot 40$ \\
\hline$\geq 25 \mathrm{~kg} / \mathrm{m}^{2}$ & 10 & 3.55 & 0.333 & $-8 \cdot 00,6 \cdot 15$ \\
\hline \multicolumn{5}{|l|}{ WC } \\
\hline$<80 / 94 \mathrm{~cm}$ & 22 & $1 \cdot 73$ & $0 \cdot 007^{\star *}$ & $-7 \cdot 65,5 \cdot 91$ \\
\hline$\geq 80 / 94 \mathrm{~cm}$ & 7 & $3 \cdot 70$ & 0.237 & $-4 \cdot 65,6 \cdot 15$ \\
\hline \multicolumn{5}{|l|}{ Video method } \\
\hline All participants & 28 & 0.95 & $0 \cdot 239$ & $-10 \cdot 14,6 \cdot 72$ \\
\hline \multicolumn{5}{|l|}{ Sex } \\
\hline Male & 13 & $1 \cdot 50$ & 0.075 & $-8 \cdot 10,6 \cdot 25$ \\
\hline Female & 15 & 0.75 & 0.925 & $-10 \cdot 30,7 \cdot 10$ \\
\hline \multicolumn{5}{|l|}{ Age } \\
\hline$\leq 26$ years & 15 & $1 \cdot 50$ & $0 \cdot 100$ & $-8 \cdot 10,6 \cdot 25$ \\
\hline$>26$ years & 13 & 0.25 & $0 \cdot 875$ & $-10 \cdot 30,7 \cdot 10$ \\
\hline \multicolumn{5}{|l|}{ BMI } \\
\hline$<25 \mathrm{~kg} / \mathrm{m}^{2}$ & 19 & 0.75 & 0.528 & $-10 \cdot 30,7 \cdot 10$ \\
\hline$\geq 25 \mathrm{~kg} / \mathrm{m}^{2}$ & 9 & 1.05 & $0 \cdot 173$ & $-8 \cdot 10,3.95$ \\
\hline \multicolumn{5}{|l|}{$w C$} \\
\hline$<80 / 94 \mathrm{~cm}$ & 23 & 0.85 & $0 \cdot 200$ & $-10 \cdot 23,6 \cdot 93$ \\
\hline$\geq 80 / 94 \mathrm{~cm}$ & 5 & $1 \cdot 05$ & 0.893 & $-4 \cdot 35,3 \cdot 30$ \\
\hline
\end{tabular}

WC, waist circumference; LOA, limits of agreement.

Significance of the difference between self- and technician WC measurements: ${ }^{\star \star} P<0.01,{ }^{* \star \star} P<0.005$.

tMedian error, the difference between self- and technician measurements (self-measured minus technician-measured). Positive indicates overestimation; negative indicates underestimation.

$\ddagger$ Wilcoxon signed-rank test for agreement between self- and technician measurements.

$\S 5$ th and 95th percentiles, non-parametric LOA ${ }^{(26)}$

written method $\left(r_{\mathrm{S}}=0.494 ; P=0 \cdot 009\right)$ and the video $\operatorname{method}\left(r_{\mathrm{S}}=0 \cdot 600 ; P=0 \cdot 001\right)$.

\section{Hip circumference}

Figure 4 illustrates the biases and limits of agreement for all participants within the written and video methods. Table 3 shows the biases and limits of agreement between self- and technician measurements for different participant characteristics within each instruction method. HC was underestimated in all sub-categories regardless of instruction method. Accuracy of HC did not differ significantly within sub-categories for sex, age, BMI or WC for either instruction method.

Participants in the written method read/watched instructions for HC significantly more times than those in the video method $(P=0 \cdot 009)$.

\section{Discussion}

In the present study WC was predominantly overestimated and HC predominantly underestimated by participants, findings consistent with previous studies ${ }^{(7,9,11,15,27,28)}$. 

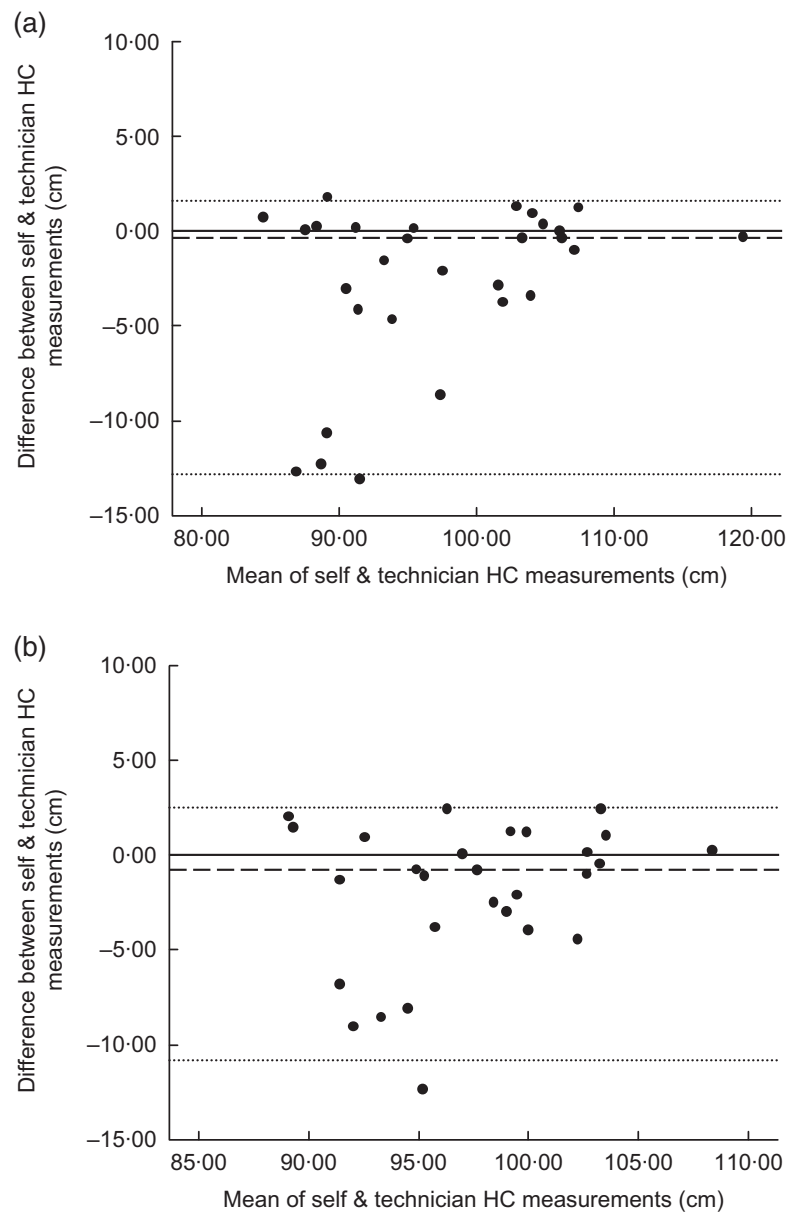

Fig. 4 Bland-Altman plot of biases of hip circumference (HC) measurement with limits of agreement, comparing selfmeasurements with technician measurements for the written method (a) and the video method (b). Negative differences indicate underestimation; positive differences indicate overestimation; _ indicates zero bias; - - - indicates median error; $\cdots$ indicates the 5 th and 95th percentile limits of agreement

Although significant biases existed within the video method, fewer significant biases were observed for both WC and HC, suggesting improved accuracy using video instruction.

Overall biases observed for WC and HC, in both the written and the video methods in the current study, are smaller than those observed in several previous studies $^{(9,12,15,27)}$, suggesting improved accuracy using the ISAK measurement protocol ${ }^{(22)}$. ISAK is an organisation which has developed international standards for anthropometric assessment and an international anthropometry accreditation scheme which aims to assist with global standardisation of anthropometry ${ }^{(22,29)}$.

Many studies have used correlational analysis in reporting reliability of self-measurements. However the use of correlations in examining accuracy of measurement may be misleading as correlation ignores any systematic bias which may be present between the
Table 3 Biases and limits of agreement of hip circumference measurements in video and written instruction methods

\begin{tabular}{|c|c|c|c|c|}
\hline & $n$ & Bias $(\mathrm{cm})+$ & $P$ value $\neq$ & LOA $(\mathrm{cm}) \S$ \\
\hline \multicolumn{5}{|l|}{ Written method } \\
\hline All participants & 29 & -0.35 & $0.009^{* *}$ & $-12 \cdot 85,1 \cdot 60$ \\
\hline \multicolumn{5}{|l|}{ Sex } \\
\hline Male & 10 & $-1 \cdot 23$ & 0.093 & $-12 \cdot 65,1 \cdot 85$ \\
\hline Female & 19 & -0.30 & 0.061 & $-13 \cdot 05,1 \cdot 35$ \\
\hline \multicolumn{5}{|l|}{ Age } \\
\hline$\leq 26$ years & 16 & $-2 \cdot 53$ & $0 \cdot 011^{*}$ & $-13 \cdot 05,1 \cdot 85$ \\
\hline$>26$ years & 13 & -0.25 & $0 \cdot 421$ & $-8 \cdot 60,1 \cdot 30$ \\
\hline \multicolumn{5}{|l|}{$\mathrm{BMI}$} \\
\hline$<25 \mathrm{~kg} / \mathrm{m}^{2}$ & 19 & $-2 \cdot 05$ & $0.005^{\star \star}$ & $-13 \cdot 05,1 \cdot 85$ \\
\hline$\geq 25 \mathrm{~kg} / \mathrm{m}^{2}$ & 10 & $-0 \cdot 10$ & 0.878 & $-8 \cdot 60,1 \cdot 35$ \\
\hline \multicolumn{5}{|l|}{ WC } \\
\hline$<80 / 94 \mathrm{~cm}$ & 22 & $-1 \cdot \cdot 78$ & $0 \cdot 008^{\star *}$ & $-12 \cdot 99,1 \cdot 72$ \\
\hline$\geq 80 / 94 \mathrm{~cm}$ & 7 & -0.25 & $0 \cdot 735$ & $-3 \cdot 70,1 \cdot 35$ \\
\hline \multicolumn{5}{|l|}{ Video method } \\
\hline All participants & 28 & -0.75 & $0.046^{*}$ & $-10 \cdot 82,2 \cdot 50$ \\
\hline \multicolumn{5}{|l|}{ Sex } \\
\hline Male & 13 & -0.95 & 0.463 & $-8 \cdot 50,2 \cdot 50$ \\
\hline Female & 15 & -0.75 & 0.078 & $-12 \cdot 30,1 \cdot 50$ \\
\hline \multicolumn{5}{|l|}{ Age } \\
\hline$\leq 26$ years & 15 & -0.75 & 0.233 & $-8 \cdot 50,2 \cdot 50$ \\
\hline$>26$ years & 13 & $-1 \cdot 25$ & $0 \cdot 108$ & $-12 \cdot 30,2 \cdot 50$ \\
\hline \multicolumn{5}{|l|}{ BMI } \\
\hline$<25 \mathrm{~kg} / \mathrm{m}^{2}$ & 19 & -0.75 & 0.235 & $-12 \cdot 30,2 \cdot 50$ \\
\hline$\geq 25 \mathrm{~kg} / \mathrm{m}^{2}$ & 9 & -0.95 & 0.051 & $-8 \cdot 50,1 \cdot 10$ \\
\hline \multicolumn{5}{|l|}{ WC } \\
\hline$<80 / 94 \mathrm{~cm}$ & 23 & -0.75 & 0.162 & $-11 \cdot 64,2 \cdot 50$ \\
\hline$\geq 80 / 94 \mathrm{~cm}$ & 5 & $-3 \cdot 90$ & $0 \cdot 138$ & $-8.05,1.25$ \\
\hline
\end{tabular}

WC, waist circumference; LOA, limits of agreement.

Significance of the difference between self- and technician $\mathrm{HC}$ measurements: ${ }^{\star} P<0.05,{ }^{\star \star} P<0.01$.

tMedian error, the difference between self- and technician measurements (self-measured minus technician-measured). Positive indicates overestimation; negative indicates underestimation.

‡Wilcoxon signed-rank test for agreement between self- and technician measurements.

\$5th and 95th percentiles, non-parametric LOA ${ }^{(26)}$.

measurements and therefore does not identify the level of agreement between two methods ${ }^{(25)}$. For this reason several studies have also used limits of agreement to examine the accuracy of self-measurement ${ }^{(6,8,11,13,15,28)}$. The limits of agreement in the current study fall within the range of those observed in previous studies. However, few previous studies ${ }^{(30,31)}$ have used the narrowest waist as a measurement location and no previous studies where this specific location has been used have examined limits of agreement; therefore any comparison of results needs to be interpreted with caution. Similarly, no previous studies have investigated limits of agreement for HC. The wide limits of agreement observed in the current study are influenced by the inclusion of outliers in the analysis. Participants who displayed extreme measurement errors were included as they represent a valid segment of the population; in epidemiological research it is likely that any population examined will comprise individuals who may demonstrate greater difficulty in understanding and implementation of instructions. Indeed, the homogeneity of the study sample towards a higher educational level may be a confounding factor. For this reason, the 
exclusion of these outliers from the analysis would result in a misrepresentation of the population and removal of participants from analysis due to higher or lower than expected values is not recommended ${ }^{(26,32)}$.

Previous studies, predominantly looking at self-reported height and weight, have demonstrated that reporting of anthropometric measures is affected by body size, age, sex and social status ${ }^{(33-35)}$. Reduced accuracy has been reported in younger ${ }^{(28)}$, older ${ }^{(6,9)}$ and male ${ }^{(28)}$ individuals. Several studies have also found greater misreporting in those with a higher body weight ${ }^{(12,27)}$, higher $\mathrm{WC}^{(9,13,27)}$ and $\mathrm{HC}^{(9)}$ and higher $\mathrm{BMI}^{(9,12,13)}$. However, in the present study, insufficient participant numbers and homogeneity in terms of BMI and WC do not permit accurate conclusions to be made with regard to accuracy according to body girth size and BMI, and future studies using larger and more heterogeneous samples are required to assess any potential differences in accuracy according to these characteristics.

In a study of a Dutch, overweight, working population $^{(28)}$ the authors reported a greater degree of accuracy among females and older participants when measuring WC. The current study provides some support for these findings; the variability observed among certain subcategories suggests that distinct populations perform differently depending on instruction format and further research is warranted to investigate if these differences persist in a more heterogeneous population.

Many previous studies have observed a tendency to underestimate WC, particularly in females, which could lead to misclassification of fat distribution and a subsequent underestimation of disease risk ${ }^{(36)}$. However, the current study demonstrates a tendency for participants to overestimate WC. This finding may be due to the measurement protocol, as the location of 'narrowest waist' significantly minimises the likelihood of underestimation.

In general, video instruction improved accuracy. However, improved accuracy of HC measurements with written instruction in certain sub-categories suggests some individuals may perform better using written instruction. The varied results may be suggestive of the potential benefit of a combined instruction format such as that used in previous research ${ }^{(15)}$, in which written and video instruction were combined into a computer-based tutorial for WC measurement, which may maximise accuracy by providing participants with a mixed instruction format. The video format used in the current study resulted in smaller bias than the prior video study ${ }^{(15)}$ in all sub-categories analysed, suggesting easier measurement technique using the narrowest waist as a point of reference. The location of the midpoint halfway between the lowest rib and the iliac crest was used as the reference point in devising the healthy cut-off points ${ }^{(37)}$. For this reason, cut-off points for measurements taken at the narrowest waist may need to be reviewed to enable accurate prediction of risk; studies have shown significant differences between measurements taken at the narrowest waist and other commonly used reference points ${ }^{(38)}$.

Within the video method the number of times participants watched the instructions was positively, but weakly, associated with the bias for WC, suggesting that error increased with increased viewing of the instructions an unexpected finding. This may be indicative of a poorer understanding of the appropriate anthropometric technique and should be further explored in future research. The finding that instructions for HC measurement were viewed significantly more in the written method is suggestive of improved comprehension of the measurement technique with video instruction. However, the number of times instructions were read/watched may be due to participants' willingness to devote only a given amount of time to measurements rather than representing their comprehension of the technique and must therefore be interpreted cautiously. Indeed, a significant advantage of the video instruction used in the current study, in terms of maintaining participant attention, is the short duration.

There are many potential explanations for the biases and variability of errors observed in the current study. Although all participants were provided with instructions and the appropriate materials to carry out measurements, it cannot be ascertained whether they followed the correct procedure. Errors may have resulted from misreading, incorrect positioning or 'cinching' ${ }^{(36)}$ of the tape. Preconceptions of the location of the 'waist' and 'hips' may have biased results as several participants reported that they thought WC was lower and HC higher. Previous studies have used the alternative terms 'torso' or 'abdomen' and 'buttocks ${ }^{(5,10)}$ in an attempt to minimise the effect of such preconceptions. Additionally, the type of clothing worn by participants may have affected measurements as some did not wear the requested loose, light clothing. However, this did not have an effect on WC as measurements were taken on bare skin. It may have had an impact on HC as both participants and the technician may have been unable to accurately identify the exact location of the widest protrusion of the buttocks, resulting in underestimation of girth. The observed variability of error for HC between instruction formats in different sub-categories is supportive of this.

The use of a standardised, easy-to-follow video instruction format such as that used in the present study provides a simple, inexpensive method of enabling individuals to provide accurate, reliable measurements in epidemiological studies and previous studies have demonstrated good reliability of repeated measurements by individuals ${ }^{(10,39)}$. Additionally, the use of video instruction based on a standardised technique may be beneficial in educating health-care professionals about appropriate measurement technique and healthy cut-off points. Indeed, a previous study $^{(40)}$ found there was a high level of variation among health-care professionals on the suggested specific values for a healthy waist (74-88 $\mathrm{cm}$ for females and $90-100 \mathrm{~cm}$ for males), demonstrating the need to develop more robust 
educational tools to support awareness-raising of central adiposity and its associated risks. The resulting standardisation would be beneficial to epidemiologists who rely on health-care professionals' records to monitor populations and to patients in ascertaining an accurate indication of their health risks.

\section{Conclusions}

To the authors' knowledge, the present study is the first to compare the influence of instruction format on reliability of self-measures of anthropometry. Although previous studies have shown that the use of written instruction enables individuals to reliably self-measure body girths, the findings of the current study confirm that video instruction can improve reliability and accuracy of selfmeasurement of waist girth compared with written instruction, thus providing a cheap and easy-to-use method for inclusion in epidemiological research. Future studies using larger and more diverse samples are required to provide further insight into whether video instruction can improve accuracy across a more varied population.

\section{Acknowledgements}

Source of funding: The present research received no specific grant from any funding agency in the public, commercial or not-for-profit sectors. Statement of acceptance of conditions: This submission represents original work that has not been published previously and is not being considered by another journal. Being accepted for Public Health Nutrition, it will not be published elsewhere in the same form, in English or in any other language, without the written consent of the Nutrition Society. Each author has seen and approved the contents of the submitted manuscript. Conflicts of interest: None. Author contributions: D.F.M. was responsible for the study design, data collection and analysis, and writing of the manuscript. S.C.L. was responsible for the research proposal, supervision of the study design, data collection and analysis, and writing of the manuscript. Acknowledgements: We would like to thank Dr Arthur Stewart (Deputy Director, Centre for Obesity Research and Epidemiology, Robert Gordon University, Aberdeen) for providing training in appropriate anthropometric techniques; and Mr Sid Marrekech (Manager, Educational Media Services, DELTA, Robert Gordon University, Aberdeen) and his team for their invaluable help in creating the video instructions.

\section{References}

1. Hartz AJ, Rupley DC \& Rimm AA (1984) The association of girth measurements with disease in 32,856 women. Am J Epidemiol 119, 71-80.
2. Lean MJ \& Han TS (2002) Waist worries. Am J Clin Nutr $\mathbf{7 6}$, 699-700.

3. Janssen I, Kartzmarzyk PT \& Ross R (2004) Waist circumference and not body mass index explains obesityrelated health risk. Am J Clin Nutr 79, 379-384.

4. Lissner L, Björkelund C, Heitmann BL et al. (2001) Larger hip circumference independently predicts health and longevity in a Swedish female cohort. Obes Res 9, 644-646.

5. Roberts CA, Wilder LB, Jackson RT et al. (1997) Accuracy of self-measurement of waist and hip circumference in men and women. J Am Diet Assoc 97, 534-536.

6. Han TS \& Lean MEJ (1998) Self-reported waist circumference compared with the 'Waist Watcher' tape-measure to identify individuals at increased health risk through intraabdominal fat accumulation. Br J Nutr 80, 81-88.

7. Tehard B, van Liere MJ, Com Nougué C et al. (2002) Anthropometric measurements and body silhouette of women: validity and perception. J Am Diet Assoc 102, 1779-1784.

8. Prince SA, Janssen I \& Tranmer JE (2008) Self-measured waist circumference in older patients with heart failure: a study of validity and reliability using a MyoTape. J Cardiopulm Rehabil Prev 28, 43-47.

9. Spencer EA, Roddam AW \& Key TJ (2004) Accuracy of selfreported waist and hip measurements in 4492 EPIC-Oxford participants. Public Health Nutr 7, 723-727.

10. Kushi LH, Kaye SA, Folsom AR et al. (1988) Accuracy and reliability of self-measurement of body girths. $\mathrm{Am} \mathrm{J}$ Epidemiol 128, 740-748.

11. Koh-Banerjee P, Chu NF, Spiegelman D et al. (2003) Prospective study of the association of changes in dietary intake, physical activity, alcohol consumption, and smoking with 9-y gain in waist circumference among 16587 US men. Am J Clin Nutr 78, 719-727.

12. Cullum A, McCarthy A, Gunnell D et al. (2004) Dietary restraint and the mis-reporting of anthropometric measures by middle-aged adults. Int J Obes Relat Metab Disord 28, 426-433.

13. Bigaard J, Spanggaard I, Thomsen BL et al. (2005) Selfreported and technician-measured waist circumferences differ in middle-aged men and women. J Nutr 135, 2263-2270.

14. Chandler P, Cooper G, Pollock E et al. (1998) Applying Cognitive Psychology Principles to Education and Training. http://www.aare.edu.au/98pap/cha98030.htm （accessed August 2010).

15. Elliott WL (2008) Criterion validity of a computer-based tutorial for teaching waist circumference self-measurement. J Bodyw Mov Ther 12, 133-145.

16. Renton-Harper P, Addy M, Warren $\mathrm{P}$ et al. (1999) Comparison of video and written instructions for plaque removal by an oscillating/rotating/reciprocating electric toothbrush. J Clin Periodontol 26, 752-756.

17. Burewicz A \& Miranowicz N (2006) Effectiveness of multimedia laboratory instruction. Chem Educ Res Pract 7, 1-12.

18. Tait AR, Voepel-Lewis T, Moscucci M et al. (2009) Patient comprehension of an interactive, computer-based information program for cardiac catheterisation: a comparison with standard information. Arch Intern Med 169, 1907-1914.

19. Office For National Statistics (2009) Internet Access: Households and Individuals 2009. http://www.statistics. gov.uk/pdfdir/iahi0809.pdf (accessed August 2010).

20. Office For National Statistics (2010) Consumer Durables. http://www.statistics.gov.uk/CCI/nugget.asp?ID = 868\&Pos $=$ $1 \&$ ColRank $=2 \&$ Rank $=480$ (accessed August 2010).

21. Norris AC (editor) (2002) Scope, benefits and limitations of telemedicine. In Essentials of Telemedicine and Telecare, pp. 19-38. Chichester: John Wiley \& Sons Ltd. 
22. International Society for the Advancement of Kinanthropometry (2006) International Standards for Anthropometric Assessment. Potchefstroom: ISAK.

23. Mavroeidi A, Macdonald HM, Stewart AD et al. (2004) Validity and repeatability of the Aberdeen bone specific physical activity questionnaire (abstract). Osteoporos Int 15, Suppl. 2, S30

24. National Institute for Health and Clinical Excellence (2006) Obesity: Guidance on the prevention, identification, assessment and management of overweight and obesity in adults and children. http://www.nice.org.uk/nicemedia/ pdf/CG43NICEGuideline.pdf (accessed August 2010).

25. Bland JM \& Altman DG (1986) Statistical methods for assessing agreement between two methods of clinical measurement. Lancet i, 307-310.

26. Bland JM \& Altman DG (1999) Measuring agreement in method comparison studies. Stat Methods Med Res 8, 135-160.

27. Weaver TW, Kushi LH, McGovern PG et al. (1996) Validation study of self-reported measures of fat distribution. Int J Obes Relat Metab Disord 20, 644-650.

28. Dekkers JC, van Wier MF, Hendriksen IJM et al. (2008) Accuracy of self-reported body weight, height and waist circumference in a Dutch overweight working population. BMC Med Res Methodol 8, 1-13.

29. International Society for the Advancement of Kinanthropometry (2010) Welcome to ISAK (home page). http:// www.isakonline.com/ (accessed August 2010).

30. Freudenheim JL \& Darrow SL (1991) Accuracy of selfmeasurement of body fat distribution by waist, hip, and thigh circumferences. Nutr Cancer 15, 179-186.

31. Mavroeidi A, Stewart AD, Macdonald HM et al. (2004) Accuracy of self-measured height, weight, waist and hip circumference in women with musculoskeletal diseases (abstract). Presented at Pre-Olympic Games Congress, Thessaloniki, Greece, 6-11 August 2004 (CD-ROM).

32. Petrie A \& Sabin C (editors) (2009) Error checking and outliers. In Medical Statistics at a Glance, 3rd ed., pp. 17-18. Chichester: John Wiley \& Sons Ltd.

33. Bostrom G \& Diderichsen F (1997) Socioeconomic differentials in misclassification of height, weight and body mass index based on questionnaire data. Int J Epidemiol 26, 860-866.

34. Kuczmarski MF, Kuczmarski RJ \& Najjar M (2001) Effects of age on validity of self-reported height, weight, and body mass index: findings from the third National Health and Nutrition Examination Survey, 1988-1994. J Am Diet Assoc 101, 28-34.

35. Spencer EA, Appleby PN, Davey GK et al. (2002) Validity of self-reported height and weight in 4808 EPIC-Oxford participants. Public Health Nutr 5, 561-565.

36. Hall TR \& Young TB (1989) A validation study of body fat distribution determined by self-measurement of waist and hip circumference. Int J Obes 13, 801-807.

37. Lean ME, Han TS \& Morrison CE (1995) Waist circumference as a measure for indicating need for weight management. BMJ 311, 158-161.

38. Wang J, Thornton JC, Bari S et al. (2003) Comparisons of waist circumferences measured at 4 sites. Am J Clin Nutr 77, 379-384.

39. Rimm EB, Stampfer MJ, Colditz GA et al. (1990) Validity of self-reported waist and hip circumferences in men and women. Epidemiology 1, 466-473.

40. Dunkley AJ, Stone MA, Patel N et al. (2009) Waist circumference measurement: knowledge, attitudes and barriers in patients and practitioners in a multi-ethnic population. Fam Pract 26, 365-371. 